\title{
Predictive Value of Sialidase in the Diagnosis of Sexually Transmitted Infections: a Cross-section Study Based on Vaginal Microecology Evaluation System
}

\author{
Ying Liu \\ The First Affiliated Hospital of Xi'an Jiaotong University \\ Jiatao Hao \\ The First Affiliated Hospital of Xi'an Jiaotong University \\ Haoyi Zhao \\ The First Affiliated Hospital of Xi'an Jiaotong University \\ Xiaowei Wang \\ The First Affiliated Hospital of Xi'an Jiaotong University

\section{Weihong Wang} \\ The First Affiliated Hospital of Xi'an Jiaotong University \\ Ruifang An ( $\sim$ Anruifang1220@163.com) \\ The First Affiliated Hospital of Xi'an Jiaotong University
}

\section{Research Article}

Keywords: vaginal microecology evaluation system, sexually transmitted infections, predictor, sialidase, Chlamydia trachomatis, Neisseria gonorrhoeae, Mycoplasma genitalium, bacterial vaginosis

Posted Date: April 13th, 2021

DOI: https://doi.org/10.21203/rs.3.rs-402898/v1

License: (c) (i) This work is licensed under a Creative Commons Attribution 4.0 International License. Read Full License 


\section{Abstract}

Background: The purpose of this study was to determine whether any indexes of vaginal microecology evaluation system (VMES) could predict sexually transmitted infections (STIs).

Methods: A total of 1032 women, who presented to Gynecology Outpatient Clinic of the First Affiliated Hospital of Xi'an Jiaotong University between November 2016 and November 2020, were included in the study. Incident STIs was defined as any case of Chlamydia trachomatis (CT), Mycoplasma genitalium (MG) and Neisseria gonorrhoeae (NG), and were confirmed using the RNA-based simultaneous amplification and testing (SAT) assay. VEMS is structured in two parts, one is the morphological characterizations encompassing bacterial density, flora diversity, predominant flora, pathogenic microorganisms and indicators of inflammation, the other is the functional indexes, including vaginal $\mathrm{pH}$, cleanliness, hydrogen peroxide ( $\mathrm{H} 2 \mathrm{O} 2)$, sialidase, $\beta$-glucuronidase, leukocyte esterase, and acetylglucosaminidase. Bacterial vaginosis (BV) was diagnosed by Gram stain (Nugent score). Associations were mainly assessed using logistic regression (LR).

Results: SAT assay detected STIs in 64 (6.2\%) of the 1032 samples tested and 136 (13.2\%) women had a clinical BV diagnosis using Nugent score. Multivariate logistic regression analysis revealed that women with sialidase-positive were more likely to test positive for STIs (aOR=3.081, 95\% Cl=1.586-5.984, $\mathrm{P}=0.001)$. Of 896 women without clinical BV, significant association was also found for sialidase and STIS (aOR $=4.133,95 \% \mathrm{Cl}=1.140-14.978, \mathrm{P}=0.031)$.

Conclusions: Sialidase may be a useful indicator to help clinicians identify these women who are at risk for STIs, especially in the absence of BV population.

\section{Background}

Chlamydia trachomatis (CT), Neisseria gonorrhoeae (NG) and Mycoplasma genitalium (MG) are common sexually transmitted infections (STIs) and treat mostly in the outpatient clinic in China. In 2016, the estimated number of incident cases was 124.3 million for CT, 30.6 million for NG worldwide[1]. Besides, the prevalence of MG was estimated to be $1.3 \%$ among countries with higher levels of development and $3.9 \%$ among countries with lower levels of development[2]. STIs is known to cause various complications including infertility, choronic pelvic inflammatory disease, premature delivery, neonatal encephalitis and others[3-5]. However, most carriers are asymptomatic and still transmissible, making the identification and diagnosis of patients with STIs a public health issue[6-8].

Vaginal microecology evaluation system (VMES) has gained popularity in China recently due to its effective, inexpensive and quick to conduct. Wet preparations of vaginal swab samples that are examined microscopically and stained by Gram staining are studied using the tool. It consists of two parts, one is the morphological characterizations encompassing bacterial density, flora diversity, predominant flora, pathogenic microorganisms and indicators of inflammation, the other is the functional indexes, including vaginal $\mathrm{pH}$, cleanliness, hydrogen peroxide $(\mathrm{H} 2 \mathrm{O} 2)$ and activity of sialidase, $\beta$ - 
glucuronidase, leukocyte esterase, and acetylglucosaminidase[9]. In 2016, infectious Disease collaborative group of Obstetrics and Gynecology Branch in Chinese Medical Association proposed the standard VMES and published the expert consensus (Table 1)[10]. The evaluation of the vaginal microecosystem can help the clinician to make a prompt diagnosis and provide new opportunities for the comprehensive management of dysbacteriosis.

Table 1

Vaginal microecology evaluation system

\begin{tabular}{|c|c|c|}
\hline Variable & Normal & Abnormal \\
\hline \multicolumn{3}{|l|}{$\begin{array}{l}\text { Morphological } \\
\text { indicators }\end{array}$} \\
\hline \multirow[t]{2}{*}{ Bacterial density } & $\|(10-100 /$ field $)$ & $\mathrm{I}(1-10 /$ field $)$ \\
\hline & $\begin{array}{l}\text { IIII(100- } \\
1000 / \text { field })\end{array}$ & IV(> 1000/field $)$ \\
\hline \multirow[t]{2}{*}{ Flora diversity } & $\begin{array}{l}\|(4-6 \text { types/ } \\
\text { field) }\end{array}$ & $\mathrm{I}(1-3$ types/ field) \\
\hline & $\begin{array}{l}\text { III(7-9 types/ } \\
\text { field) }\end{array}$ & IV(> 10 types/ field) \\
\hline \multirow{3}{*}{$\begin{array}{l}\text { Predominant } \\
\text { flora* }^{*}\end{array}$} & \multirow{3}{*}{$\begin{array}{l}\text { Large Gram- } \\
\text { positive rods }\end{array}$} & Gram-positive cocci \\
\hline & & Large Gram-negative rods \\
\hline & & Small Gram-negative rods \\
\hline BV (Nugent score) & $1-6$ & $\geq 7$ \\
\hline AV score & $<3$ & $\geq 3$ \\
\hline Pathogen & Negative & $\begin{array}{l}\text { Fungus (spore, budding yeast, or hyphal forms) and } \\
\text { trichomonads }\end{array}$ \\
\hline \multicolumn{3}{|l|}{$\begin{array}{l}\text { Functional } \\
\text { indicators }\end{array}$} \\
\hline Vaginal $\mathrm{PH}$ & $\geq 3.8$ and $<4.5$ & $<3.8$ or $\geq 4.5$ \\
\hline $\mathrm{H} 2 \mathrm{O} 2$ & Negative & Positive \\
\hline $\begin{array}{l}\text { Vaginal preformed } \\
\text { enzymes }\end{array}$ & Negative & $\begin{array}{l}\text { Positive for sialidase, } \beta \text {-glucuronidase, leukocyte esterase, } \\
\text { and acetylglucosaminidase }\end{array}$ \\
\hline \multicolumn{3}{|c|}{$\begin{array}{l}\text { *Large Gram-positive rods: Lactobacillus, Gram-positive cocci: Staphylococcus aureus, } \\
\text { Staphylococcus epidermidis; Gram-negative rods: Escherichia coli. }\end{array}$} \\
\hline
\end{tabular}


In the resource constrained settings of many developing countries, screening tests for STIs using culture, ELISA, and polymerase chain reaction are not practical options because of their costs or procedures[1113]. Given this, there is a clinical need for a cheap, rapid, and simple assay that would allow clinicians to make an early predictive diagnosis during the initial patient visit. Therefore, we evaluated whether any indexes of VMES that could predict the presence of STIs.

\section{Methods}

\subsection{Subjects and study design}

A cross-sectional study was conducted in Gynecology Outpatient Clinic of the First Affiliated Hospital of Xi'an Jiaotong University between November 2016 and November 2020. Prior to data collection, participants $\geq 16$ years signed written informed consent, and those $<16$ years provided assent and parental consent from their parents/guardians. The study protocol was approved by the ethics Committee of the First Affiliated Hospital of Xi'an Jiaotong University. Collected information including age, status of their pregnancy, main symptoms (color and amount of discharge, itching, burning pain, urodynia, etc), medical history before gynecological examination. All had simultaneous STIs test(including CT, MG and NG)using the RNA-based SAT and vaginal microecology evaluation based on VMES. The exclusion criteria were: (1) Women during menstrual period; (2) women received hormones, antibiotic or immunosuppressive agents within 2 weeks; (3) women had a history of vulva or vaginal medication in the last 7 days. Eligible patients were required to complete a comprehensive gynecologic examination after collecting the basic information. Samples of vaginal fluid from the lateral vaginal walls were obtained using two sterile cotton swabs, one was used for the functional detection of vaginal microecology evaluation, another vaginal swab was streaked on a glass slide and air dried to Gram stain for morphological interpretations. Additionally, a long sterile cotton swab was used to collect the endocervical samples for the test of STIs. All samples were taken to the laboratory for testing immediately.

\subsection{Vaginal microecology evaluation system}

(1) Microscopic evaluation on Gram-stained vaginal smears:

(A) Bacterial density: it refers to the average number of bacteria in the microscopic field under oil immersion lens. The results were classified into four levels(denoted as + to ++++): grade I (+): 1-9; grade II (++): 10-99; grade III (+++): 100 and above; and grade IV: (++++): bacteria clustered full of vision. Both "++" and "+++" mean normal.

(B) Flora diversity: it refers to the number of distinguishable bacterial species under oil immersion lens. The results were also divided into four levels (denoted as + to ++++$)$ : grade I (+): 1-3 kinds of flora; grade II (++): 4- 6 kinds of flora; grade III (+++): 7-10 kinds of flora; and grade IV (++++): more than 10 kinds of flora. "++" and "+++" were viewed as normal. 
(C) Predominant flora: it refers to the maximum number of microorganism observed in the microscopic field under oil immersion lens. Only Large Gram-positive rods (Lactobacillus) was determined as a normal flora.

(D) Vaginal cleanliness evaluation: It was graded by the density of Lactobacillus, epithelial cells, white blood cells, other flora into 4 levels, with Grade I-II as normal and grades III-IV as abnormal usually accompanied by inflammation. Specifically, the judgment of vaginal cleanliness were as follows (Table S1) [14]: Grade I was a large number of large Gram-positive rods (indicative of Lactobacillus spp.), vaginal epithelial cells, and no other bacteria observed with WBC $0-5 / \mathrm{HP}$ under microscopy. Grade II was some Lactobacillus spp. and vaginal epithelial cells, some pus cells, and other bacteria observed under microscopy with WBC 10-15/HP. Grade III was a small amount of Lactobacillus spp., a large number of pus cells, and other bacteria observed under microscopy with WBC 15-30/HP. Grade IV was no Lactobacillus spp. but pus cells and other bacteria observed under microscopy with WBC more than 30/HP[14](Table S1).

(E) Bacterial vaginosis (BV) was assessed by Nugent score and a score of 7 to 10 was defined as BV[15] (Table S2). Aerobic vaginitis (AV) were assessed by VMES according to the AV score[9, 10](Table S3).

(F) Pathogen: TV (Trichomonas vaginosis) was diagnosed by motile flagellates under a microscope and VVC (vulvovaginal candidiasis) was confirmed when the yeast and(or) pseudohyphae were observed through a microscope.

(2) Functional detection of vaginal microecology evaluation:

(A) Vaginal preformed enzymes: $\mathrm{H} 2 \mathrm{O} 2$, sialidase, $\beta$-glucuronidase, leukocyte esterase, and acetylglucosaminidase were detected following manufacturer's directions (Chaoshi-Bio, Jiangsu China). All these enzymes were classified as positive or negative result.

(B) Vaginal $\mathrm{pH}$ : $\mathrm{pH}$ paper strips ranging from 3.8 to 5.4 were used to measure the vaginal $\mathrm{pH}$. The normal vaginal $\mathrm{pH}$ values range from 3.8 to 4.5 .

\subsection{Detection of STIs}

CT, NG and MG were detected utilizing the RNA-based SAT (simultaneous amplification and testing) assay and STIs was considered positive if any of CT, MG, NG test was positive.

\subsection{Statistical analyses}

Differences in study population characteristics were tested using the $\chi 2$, Fisher exact or Mann-Whitney $U$ test, accordingly. The unadjusted odds ratios (ORs) were obtained from an unconditional, binary logistic model with only one dichotomous covariate of interest in the model. All variables associated with the outcome (STIs) at $P<0.1$ were entered into the logistic regression model. Then stepwise backward elimination logistic regression was performed to determine which factors were independently associated with STIs, and the final reduced model was constructed. P values $<0.05$ were considered significant. 
Finally, we also presented the results in the subset of women without BV using the stepwise backward elimination logistic regression. We obtained the unadjusted and adjusted log odds using computer software (IBM SPSS version 25).

\section{Results}

\subsection{Study Population}

Of the 1032 women included, all belonged to Han Chinese ethnicity from northwestern China, 563 attended with clinical symptoms of urogenital symptoms such as "itching" "abnormal vaginal discharge" or "cervicitis" and others visited for pre-pregnancy examination, abortion history or pelvic inflammation, etc. They ranged in age from 15 to 68 years (mean age $=30$ ) and $18.4 \%$ of subjects under 25 years old. $64(6.2 \%)$ participates were diagnosed with STIs and there were 32 cases of CT,17 cases of MG, and 16 cases of NG.

\subsection{STIs and Other reproductive tract infections}

Nugent score confirmed that 136 of the 1032 patients had BV and these subjects were more likely to be STIs-positive than subjects without BV. In univariable analyses, we found that BV(Nugent score $\geq 7$ ) was associated with a 1.9 -fold increase $(\mathrm{OR}=1.942,95 \% \mathrm{Cl}=1.042-3.618, \mathrm{P}=0.037)$ in the odds of incident STIs. In addition, the STIs-positive and STIs-negative groups were similar in TV, VVC or AV (Table 2). 
Table 2

Subject Characteristics and Predictor Variables Stratified by STIs Status

\section{Characteristic}

\section{STIs Results}

$\begin{array}{llll}\text { Total } & \text { Positive (\%) } & \text { Negative (\%) } & \text { P-value } \\ (\mathrm{N}=1032) & (\mathrm{N}=64) & (\mathrm{N}=968) & \end{array}$

Age (y)

$\leq 25$

192

840

$>25$

Urogenital symptoms

Yes

No

\section{Morphological indicators}

Pathogen

BV(Nugent Score)

Positive

Negative

VVC

Positive

Negative

TV

Positive

Negative

AV

Positive

Negative

Bacterial density

Normal

Abnormal
563

469
$<0.001$

\begin{tabular}{ll}
$31(48.4 \%)$ & $161(16.6 \%)$ \\
\hline $33(51.6 \%)$ & $807(83.4 \%)$
\end{tabular}

0.310

31(48.4\%)

532(55.0\%)

$33(51.6 \%)$ 


\begin{tabular}{|c|c|c|c|c|}
\hline \multirow[t]{3}{*}{ Characteristic } & \multicolumn{4}{|c|}{ STIs Results } \\
\hline & Total & Positive (\%) & Negative (\%) & P-value \\
\hline & $(N=1032)$ & $(N=64)$ & $(\mathrm{N}=968)$ & \\
\hline Flora diversity & & & & 1.000 \\
\hline Normal & 985 & $61(95.3 \%)$ & $924(95.6 \%)$ & \\
\hline Abnormal & 46 & $3(4.7 \%)$ & $43(4.4 \%)$ & \\
\hline Predominant flora & & & & $<0.001$ \\
\hline Normal & 669 & $28(43.8 \%)$ & $641(66.2 \%)$ & \\
\hline Abnormal & 363 & $36(56.3 \%)$ & $327(33.8 \%)$ & \\
\hline Vaginal cleanliness & & & & 0.225 \\
\hline Normal & 775 & $44(68.8 \%)$ & $731(75.5 \%)$ & \\
\hline Abnormal & 257 & $20(31.3 \%)$ & $237(24.5 \%)$ & \\
\hline \multicolumn{5}{|l|}{ Functional indicators } \\
\hline Vaginal PH & & & & 0.012 \\
\hline Normal & 237 & $6(10.3 \%)$ & $231(24.8 \%)$ & \\
\hline Abnormal & 752 & $52(89.7 \%)$ & $700(75.2 \%)$ & \\
\hline $\mathrm{H} 2 \mathrm{O} 2$ & & & & 1.000 \\
\hline Positive & 982 & $60(96.8 \%)$ & 922(96.8\%) & \\
\hline Negative & 32 & $2(3.2 \%)$ & $30(3.2 \%)$ & \\
\hline Sialidase & & & & $<0.001$ \\
\hline Positive & 109 & $18(28.1 \%)$ & $91(9.4 \%)$ & \\
\hline Negative & 923 & $46(71.9 \%)$ & $877(90.6 \%)$ & \\
\hline Leukocyte esterase & & & & 0.078 \\
\hline Positive & 669 & $48(75.0 \%)$ & $621(64.2 \%)$ & \\
\hline Negative & 363 & $16(25.0 \%)$ & $347(35.8 \%)$ & \\
\hline$\beta$-glucuronidase & & & & 1.000 \\
\hline Positive & 2 & $0(0.0 \%)$ & $2(0.2 \%)$ & \\
\hline
\end{tabular}

STIs: Sexually transmitted infections, BV: Bacterial vaginosis; TV: Trichomonas vaginalis; VVC: vulvovaginal candidiasis, AV: Aerobic vaginitis; $\mathrm{H} 2 \mathrm{O} 2$ : hydrogen peroxide 


\begin{tabular}{|c|c|c|c|c|}
\hline \multirow[t]{3}{*}{ Characteristic } & \multicolumn{4}{|c|}{ STIs Results } \\
\hline & Total & Positive (\%) & Negative (\%) & P-value \\
\hline & $(N=1032)$ & $(N=64)$ & $(N=968)$ & \\
\hline Negative & 1030 & $64(100.0 \%)$ & $966(99.8 \%)$ & \\
\hline Acetylglucosaminidase & & & & 0.001 \\
\hline Positive & 76 & $12(18.8 \%)$ & $64(6.6 \%)$ & \\
\hline Negative & 956 & $52(81.3 \%)$ & 904(93.4) & \\
\hline
\end{tabular}

\subsection{Other Characteristics Associated with STIs by univariable analysis}

In univariable analysis, younger age (15-25y), abnormal bacterial density, abnormal predominant flora, vaginal $\mathrm{pH}>4.5$, sialidase-positive and acetylglucosaminidase-positive were strongly associated with the positive result of STIs $(P<0.05)$, a nonsignificant trend was observed between positive STIs test results and leukocyte esterase $(P=0.078)$, no associations were found between STIs and urogenital symptoms, flora diversity, $\mathrm{H} 2 \mathrm{O} 2, \beta$-glucuronidase, cleanliness ( $P>0.1$ ) (Table 2).

\subsection{Multivariate logistic regression analysis}

Because the individual markers (bacterial density and predominant flora) that connected to the Nugent score had independent associations with STIs, the individual markers rather than the composite variable "BV" were used in the final logistic regression model. After adjustment for predominant flora, bacterial density, vaginal PH, Leukocyte esterase and acetylglucosaminidase, the multivariate logistic regression model revealed that sialidase-positive and younger age (15-25y) were independently associated with STIs. Sialidase-positive was significantly associated with an increased odds of STIS ( $\mathrm{aOR}=3.08 ; 95 \% \mathrm{Cl}$ $=1.586-5.984, P=0.001)$. Further, younger subjects $(15-25 y)$ were 5.1 times more likely to be infected with STIs $(\mathrm{aOR}=5.042,95 \% \mathrm{Cl}, 2.890-8.798, \mathrm{P}=0.001)($ Table 3$)$. 
Table 3

Univariable and Multivariable Logistic Regression Analyses of Characteristics Associated STIs

\begin{tabular}{|c|c|c|c|c|}
\hline \multirow[t]{2}{*}{ Characteristic } & \multicolumn{2}{|l|}{ Univariable } & \multicolumn{2}{|l|}{ Multivariable } \\
\hline & OR $(95 \% \mathrm{Cl})$ & $P$ Value & Adjusted OR (95\% Cl) & $P$ Value \\
\hline Age (y) & & 0.000 & & 0.001 \\
\hline$>25$ & 1 & & 1 & \\
\hline$\leq 25$ & $4.709(2.803,7.909)$ & & $5.042(2.890,8.798)$ & \\
\hline Urogenital symptoms & & 0.311 & & \\
\hline No & 1 & & & \\
\hline Yes & $0.770(0.464,1.277)$ & & & \\
\hline \multicolumn{5}{|c|}{ Morphological indicators } \\
\hline \multicolumn{5}{|l|}{ Pathogen } \\
\hline BV (Nugent Score) & & 0.037 & & \\
\hline Negative & 1 & & & \\
\hline Positive & $1.942(1.042,3.618)$ & & & \\
\hline VVC & & 0.378 & & \\
\hline Positive & 1 & & & \\
\hline Negative & $0.711(0.332,1.519)$ & & & \\
\hline TV & & 0.300 & & \\
\hline Negative & 1 & & & \\
\hline Positive & $1.661(0.637,4.332)$ & & & \\
\hline AV & & 0.883 & & \\
\hline Negative & 1 & & & \\
\hline Positive & $1.166(0.150,9.057)$ & & & \\
\hline Bacterial density & & 0.052 & & \\
\hline Normal & 1 & & & \\
\hline Abnormal & $1.824(0.995,3.341)$ & & & \\
\hline Flora diversity & & 0.928 & & \\
\hline
\end{tabular}




\begin{tabular}{|c|c|c|c|c|}
\hline \multirow[t]{2}{*}{ Characteristic } & \multicolumn{2}{|l|}{ Univariable } & \multicolumn{2}{|l|}{ Multivariable } \\
\hline & OR $(95 \% \mathrm{Cl})$ & $P$ Value & Adjusted OR (95\% Cl) & $P$ Value \\
\hline Normal & 1 & & & \\
\hline Abnormal & $1.057(0.319,3.504)$ & & & \\
\hline Predominant flora & & 0.000 & & \\
\hline Normal & 1 & & & \\
\hline Abnormal & $2.520(1.511,4.203)$ & & & \\
\hline Vaginal cleanliness & & 0.227 & & \\
\hline Normal & 1 & & & \\
\hline Abnormal & $1.402(0.810,2.426)$ & & & \\
\hline \multicolumn{5}{|l|}{ Functional indicators } \\
\hline Vaginal PH & & 0.016 & & 0.069 \\
\hline Normal & 1 & & 1 & \\
\hline Abnormal & $2.860(1.213,6.745)$ & & $2.277(0.937,5.534)$ & \\
\hline $\mathrm{H} 2 \mathrm{O} 2$ & & 0.976 & & \\
\hline Normal & 1 & & & \\
\hline Abnormal & $0.976(0.228,4.182)$ & & & \\
\hline Sialidase & & 0.000 & & 0.001 \\
\hline Normal & 1 & & 1 & \\
\hline Abnormal & $3.771(2.099,6.777)$ & & $3.081(1.586,5.984)$ & \\
\hline Leukocyte esterase & & 0.081 & & \\
\hline Normal & 1 & & & \\
\hline Abnormal & $1.676(0.938,2.997)$ & & & \\
\hline$\beta$-glucuronidase & & 0.999 & & \\
\hline Normal & 1 & & & \\
\hline Abnormal & 0.999 & $(0.000,0.000)$ & & \\
\hline Acetylglucosaminidase & & 0.001 & & 0.053 \\
\hline
\end{tabular}




\begin{tabular}{|c|c|c|c|}
\hline \multirow[t]{2}{*}{ Characteristic } & Univariable & \multicolumn{2}{|l|}{ Multivariable } \\
\hline & OR $(95 \% \mathrm{Cl})$ & Adjusted OR (95\% Cl) & $P$ Value \\
\hline Normal & 1 & 1 & \\
\hline Abnormal & $3.260(1.656,6.415)$ & $2.183(0.991,4.806)$ & \\
\hline
\end{tabular}

\subsection{The multivariate logistic regression analysis in the subset of BV negative group}

In addition, we analyzed the subset ( $n=896)$ of BV-negative group. In these subjects, 7 of $23(30.435 \%)$ with a positive sialidase tested positive for STIs, whereas only 43 of $873(4.926 \%)$ without elevated sialidase were positive for STIs. After controlling for potentially confounding factors, a similar significant trend was seen between sialidase and STIs $(\mathrm{aOR}=4.133 ; 95 \% \mathrm{Cl}=1.140-14.978, \mathrm{P}=0.031)($ Table 4$)$.

\section{Table 4}

Multivariable Logistic Regression Model for Predictors of STIs in the subset of women without BV.

\begin{tabular}{|llll|}
\hline Characteristic & OR & $95 \% \mathrm{Cl}$ & $P$ Value \\
\hline Age of 15-25 years & 4.756 & $(2.524,8.960)$ & $<0.001$ \\
\hline Vaginal PH & 2.292 & $(0.932,5.634)$ & 0.071 \\
\hline Sialidase positivity & 4.133 & $(1.140,14.978)$ & 0.031 \\
\hline Acetylglucosaminidase positivity & 2.54 & $(1.081,5.968)$ & 0.032 \\
\hline Cl: confidence interval; OR: odds ratio. & & \\
\hline
\end{tabular}

\section{Discussion}

The study focused on the relationship between STIs and indexes of vaginal microecology evaluation system in Xi'an district. We found that sialidase is strongly associated with STIs which suggests that information from VMES can be used to predict the presence of STIs. Vaginal microecology tests are inexpensive and widely available tools especially in China that may potentially help clinicians estimate which patients are at risk for STIs.

Our study demonstrates that the rates of STIs acquisition are increased in the BV affected patient and younger women, which is consistent with some previous findings about STIs[16-18]. BV is characterized by a reduced number of Lactobacillus spp. and an increased diversity of anaerobic bacterial species, 
including Gardnerella vaginalis, Atopobium vaginae, Prevotella spp., etc. There are strong biological arguments in favor of this hypothesis that BV is risk factor for STI acquisition. Firstly, Lactobacillus species protect against STIs by producing antimicrobial compounds, including organic acid to lowers the vaginal $\mathrm{pH}, \mathrm{H} 2 \mathrm{O} 2$, target-specific bacteriocins and possibly biosurfactants[19]. Thus, the lack of Lactobacillus species would result in greater susceptibility to infections. Secondly, vaginal strict and facultative anaerobes appear to produce cytokines, nitrosamines and inflammatory mediators, which are supposed to be related to cervical inflammation[20], and mucin-degrading enzymes that reduce the infection barrier[21, 22].

We identified the main factor associated with STIs was sialidase. Sialidase is an enzyme involved in the pathogenesis of several diseases by cleaving sialic acid from terminal glycans of glycoproteins and thus leading to impairment of the local immune response[23-25]. Not surprising that elevated sialidase represents an abnormal state and associated with higher risk, should these women be exposed to an STI pathogen. In former study, Briselden et studied 50 vaginal fluid specimens from women with BV and found that elevated levels of sialidase activity were detected in those with BV (84\%) than without BV (Pख0.001)[26]. Meanwhile, the results of our study also showed a strong correlation between BV and sialidase. Furthermore, increased sialidase activity has been detected in the vaginal fluid of BV patients[26, 27], and is the basis of a marketed quick test for diagnosis of BV[28]. Therefore, then we also focused on the subjects of BV-negative group. We find that women with sialidase-positive have higher prevalence of STIs compared with those without sialidase positivity even in the BV negativity group, and $30 \%$ of those with an elevated sialidase were infected with STIs in subset of women without BV, which demonstrating sialidase-positive associated with the vulnerability to STIs regardless of the BV. Therefore, sialidase may be a better predictor of STIs than BV.

However, these findings may be somewhat limited by lacking some other possible determinants and confounders for the acquisition of STIs, such as sexual risk behavior, previous STIs, condom use. Another limitation of this study is that the cross-sectional design limits our ability to interpret the associations we found and we cannot determine whether STIs cause an elevated vaginal sialidase or if women with high vaginal sialidase are more susceptible to STIs. Besides, the low prevalence of STIs in this study came as a surprise, compared to the prevalence in other parts of the world[1]. It might be explained that more than four in five of participants over age 25 . Thus, the study should be repeated with a larger group of women to confirm our results due to the lack of positive samples.

\section{Conclusions}

Overall, our study supports that sialidase is a feasible option to predict the people who need to be further NAATs examined, especially in the absence of BV. In view of this, the VMES may offer great potential for prediction in diagnosis of infectious disease. It is noteworthy that the quick prediction and diagnosis of STIs is key to propose a comprehensive approach to sexual and reproductive health.

\section{Abbreviations}


STIs: Sexually transmitted infections; VMES: vaginal microecology evaluation system; CT: Chlamydia trachomatis; MG: Mycoplasma genitalium; NG: Neisseria gonorrhoeae, BV: Bacterial vaginosis; TV: Trichomonas vaginalis; VVC: Vulvovaginal candidiasis; AV『Aerobic vaginitis; SAT: simultaneous amplification and testing; $\mathrm{H} 2 \mathrm{O} 2$ : hydrogen peroxide

\section{Declarations}

\subsection{Ethics approval and consent to participate}

This study was conducted in accordance with the declaration of Helsinki. Prior to data collection, participants $\geq 16$ years signed written informedconsent, and those $<16$ years provided assent andparentalconsent from their parents/guardians. The study protocol was approved by the ethics committee of the First Affiliated Hospital of Xi'an Jiaotong University.

\subsection{Consent for publication}

Not applicable.

\subsection{Availability of data and materials}

The datasets used and analyzed in this study are available from the corresponding author on reasonable request.

\subsection{Competing interest}

The authors declare that they have no competing interests.

\subsection{Funding}

This study was supported by Shaanxi Science and Technology Coordinating Innovation Plan (no. 2016KTCL03-06) and Clinical research project of the First Affiliated Hospital of Xi'an Jiaotong University (no. XJTUIAF-CRF-2015-019).

\subsection{Authors' Contributions}

LY designed of the work; ZHY, WXW, WWH performed the case and sample collection, analysis, and interpretation of the data; LY, HJT have drafted the work or substantively revised it; ARF reviewed and approved the final manuscript. All authors have read and approved the final manuscript. 


\subsection{Acknowledgements}

Not applicable.

\section{References}

1. Rowley J, Vander Hoorn S, Korenromp E, Low N, Unemo M, Abu-Raddad LJ, Chico RM, Smolak A, Newman L, Gottlieb S et al: Chlamydia, gonorrhoea, trichomoniasis and syphilis: global prevalence and incidence estimates, 2016. Bulletin of the World Health Organization 2019, 97(8):548-562p.

2. Gnanadurai R, Fifer H: Mycoplasma genitalium: A Review. Microbiology (Reading, England) 2020, 166(1):21-29.

3. Land JA, Evers JL: Chlamydia infection and subfertility. Best practice \& research Clinical obstetrics \& gynaecology 2002, 16(6):901-912.

4. Moodley P, Sturm AW: Sexually transmitted infections, adverse pregnancy outcome and neonatal infection. Seminars in neonatology : SN 2000, 5(3):255-269.

5. Mullick S, Watson-Jones D, Beksinska M, Mabey D: Sexually transmitted infections in pregnancy: prevalence, impact on pregnancy outcomes, and approach to treatment in developing countries. Sexually transmitted infections 2005, 81(4):294-302.

6. Korenromp EL, Sudaryo MK, de Vlas SJ, Gray RH, Sewankambo NK, Serwadda D, Wawer MJ, Habbema JD: What proportion of episodes of gonorrhoea and chlamydia becomes symptomatic? International journal of STD \& AIDS 2002, 13(2):91-101.

7. Chen XS, Yin YP, Chen LP, Thuy NT, Zhang GY, Shi MQ, Hu LH, Yu YH: Sexually transmitted infections among pregnant women attending an antenatal clinic in Fuzhou, China. Sexually transmitted diseases 2006, 33(5):296-301.

8. Wilkinson D, Abdool Karim SS, Harrison A, Lurie M, Colvin M, Connolly C, Sturm AW: Unrecognized sexually transmitted infections in rural South African women: a hidden epidemic. Bulletin of the World Health Organization 1999, 77(1):22-28.

9. Li T, Liu ZH, Li K, Bai HH: Evaluation of the vaginal microbiome in clinical diagnosis and management of vaginal infectious diseases. Chinese medical journal 2019, 132(9):1100-1103.

10. Infectious Disease Cooperative Group BoOaG, Chinese Medical Association.: Clinical practice of vaginal microecology evaluation system, committee opinion (in Chinese). In: Chin J Obstet Gynecol. vol. 51, 2016/10/30 edn; 2016: 721-723.

11. Herbst de Cortina S, Bristow CC, Joseph Davey D, Klausner JD: A Systematic Review of Point of Care Testing for Chlamydia trachomatis, Neisseria gonorrhoeae, and Trichomonas vaginalis. Infectious diseases in obstetrics and gynecology 2016, 2016:4386127.

12. Kelly H, Coltart CEM, Pant Pai N, Klausner JD, Unemo M, Toskin I, Peeling RW: Systematic reviews of point-of-care tests for the diagnosis of urogenital Chlamydia trachomatis infections. Sexually transmitted infections 2017, 93(S4):S22-s30. 
13. Hardick J, Giles J, Hardick A, Hsieh YH, Quinn T, Gaydos C: Performance of the gen-probe transcription-mediated [corrected] amplification research assay compared to that of a multitarget real-time PCR for Mycoplasma genitalium detection. Journal of clinical microbiology 2006, 44(4):1236-1240.

14. Yue $X A$, Chen $P$, Tang $Y, W u X, H u Z$ : The dynamic changes of vaginal microecosystem in patients with recurrent vulvovaginal candidiasis: a retrospective study of $\mathbf{8 0 0}$ patients. Arch Gynecol Obstet 2015, 292(6):1285-1294.

15. Nugent RP, Krohn MA, Hillier SL: Reliability of diagnosing bacterial vaginosis is improved by a standardized method of gram stain interpretation. Journal of clinical microbiology 1991, 29(2):297301.

16. Wiesenfeld HC, Hillier SL, Krohn MA, Landers DV, Sweet RL: Bacterial vaginosis is a strong predictor of Neisseria gonorrhoeae and Chlamydia trachomatis infection. Clinical infectious diseases : an official publication of the Infectious Diseases Society of America 2003, 36(5):663-668.

17. Brotman RM, Klebanoff MA, Nansel TR, Yu KF, Andrews WW, Zhang J, Schwebke JR: Bacterial vaginosis assessed by gram stain and diminished colonization resistance to incident gonococcal, chlamydial, and trichomonal genital infection. The Journal of infectious diseases 2010, 202(12):1907-1915.

18. Allsworth JE, Peipert JF: Severity of bacterial vaginosis and the risk of sexually transmitted infection. American journal of obstetrics and gynecology 2011, 205(2):113.e111-116.

19. Boris S, Barbés $\mathrm{C}$ : Role played by lactobacilli in controlling the population of vaginal pathogens. Microbes and infection 2000, 2(5):543-546.

20. Boyle DC, Barton SE, Uthayakumar S, Hay PE, Pollock JW, Steer PJ, Smith JR: Is bacterial vaginosis associated with cervical intraepithelial neoplasia? International journal of gynecological cancer: official journal of the International Gynecological Cancer Society 2003, 13(2):159-163.

21. Olmsted SS, Meyn LA, Rohan LC, Hillier SL: Glycosidase and proteinase activity of anaerobic gramnegative bacteria isolated from women with bacterial vaginosis. Sexually transmitted diseases 2003, 30(3):257-261.

22. Lamont RF, Sobel JD, Akins RA, Hassan SS, Chaiworapongsa T, Kusanovic JP, Romero R: The vaginal microbiome: new information about genital tract flora using molecular based techniques. BJOG : an international journal of obstetrics and gynaecology 2011, 118(5):533-549.

23. Pilatte $Y$, Bignon J, Lambré CR: Sialic acids as important molecules in the regulation of the immune system: pathophysiological implications of sialidases in immunity. Glycobiology 1993, 3(3):201-218.

24. Wiggins R, Hicks SJ, Soothill PW, Millar MR, Corfield AP: Mucinases and sialidases: their role in the pathogenesis of sexually transmitted infections in the female genital tract. Sexually transmitted infections 2001, 77(6):402-408.

25. Lewis WG, Robinson LS, Perry J, Bick JL, Peipert JF, Allsworth JE, Lewis AL: Hydrolysis of secreted sialoglycoprotein immunoglobulin A ( $\operatorname{lgA})$ in ex vivo and biochemical models of bacterial vaginosis. The Journal of biological chemistry 2012, 287(3):2079-2089. 
26. Briselden AM, Moncla BJ, Stevens CE, Hillier SL: Sialidases (neuraminidases) in bacterial vaginosis and bacterial vaginosis-associated microflora. Journal of clinical microbiology 1992, 30(3):663-666.

27. Moncla BJ, Chappell CA, Debo BM, Meyn LA: The Effects of Hormones and Vaginal Microflora on the Glycome of the Female Genital Tract: Cervical-Vaginal Fluid. PloS one 2016, 11(7):e0158687.

28. Huppert JS, Hesse EA, Bernard MC, Bates JR, Gaydos CA, Kahn JA: Accuracy and trust of self-testing for bacterial vaginosis. The Journal of adolescent health : official publication of the Society for Adolescent Medicine 2012, 51(4):400-405.

\section{Supplementary Files}

This is a list of supplementary files associated with this preprint. Click to download.

- Supplementaryinformation.pdf 